\title{
The Risk of PPP Project and Demand for Lawyers from the Perspective of China
}

\author{
Lei Wei ${ }^{\mathrm{a}}$, Zhaohui Chen ${ }^{\mathrm{b}}$ \\ School of Law and Economy, Bohai University, Jinzhou, 121013, China \\ a913238595@qq.com, b14507229@qq.com
}

Keywords: PPP Project; government; lawyer; risk; requirements; consultation

\begin{abstract}
PPP project is an innovative way of cooperation, which not only bring out internal economic development but also improve people's livelihood in the same time. Even though it seems to be a noble concept, it is inevitable to encounter some obstacles and difficulties. This essay generally split into several parts: first of all, a brief introduction will be brought to illustrate the nature and situation of PPP projects in China; then, the paper analyzes the existing risks and challenges in China. Also, this paper has the advantage that it allows ones to take into consideration new demands and challenges that lawyers faced with in their business work nowadays, it concludes that traditional working mode will need a little bit adjustment and improvement, which eventually helps operate PPP project and construct a sustainable society in a better way.
\end{abstract}

\section{Introduction}

PPP shorts for "Public Private Partnerships", which means cooperation between government and social capital. PPP is a very broad concept, in a wider perspective, it refers to a variety of the cooperative relations amongst public sector and the private sector in the process of providing public goods and services. And in the narrow sense, PPP can be understood as an innovative way to provide financing for the project as whole.

The promotion of PPP mode in China is not only an innovation in the way of public project procurement, but also a transformation of government function character from supervisors to regulators. Local governments should recognize the essence of PPP and complete the change of concept. Technically speaking, PPP seems to be a financing model, nevertheless, it goes far more than that, it also can be viewed as a way of cooperation that helps contribute to the productivity of public utilities. In recent years, China attaches great importance to PPP model, and has issued a series of policies and regulatory documents to promote the development of PPP projects. In 2014, the State Council released the guidance opinion on encouraging social investment, which put forward the policy of "conscientiously summing up experience and strengthening policy guidance in areas such as public services, resources and environment, ecological protection and infrastructure, and actively promote the PPP model. This is the earliest domestic policy on PPP projects in China [1].

\section{Background}

Due to bunches of incentive policies and regulations, PPP projects came into blossom and prosperity time, which render heated discussion among academic colleagues about the neglect of hidden risk behind PPP project, as well as a huge crisis. Risk is an element full of uncertainty, a probability of loss and a probabilistic cause. Because of the large scale and long-term investment of the PPP projects, many participants such as government and social capital have been involved, and their willingness and ability of taking risks diversify from each other because their starting points and ultimate purpose are different. Therefore, proper risk pre-prevention and rational responsibility assumption become the key factor in accomplishing the project, and social public interest is closely related.

Insights from its inner mechanism, the risk of PPP can be divided into three levels: the macro level risk, the middle level risk and the micro level risk. The macro-level risks stem from external 
causes, such as national legislation and industry development, which mainly concentrated in the legal environment, economic environment, social environment as well as climate environment. The risks at the meso-level includes risks derive from the project itself, most of them are implementation issues, including aspects like project requirements, address, design and construction. At the micro level, empirical evidence proves that risks are arising from the various interest relationships formed during cooperation. The distinctions between the public and private parties in contract management can provide a perfect answer for this kind of risk.

\section{Potential Risks}

(1) From the date of birth, there is an important legal risk, that is the ambiguous definition of PPP contract. Is it an administrative contract or a civil contract? Because it is directly related to, once the cooperation has a contradiction, what kind of law should be used ultimately. Some commentators have suggested that if the contract is based on public law, then social capital, can only ask for administrative reconsideration or administrative proceedings to protect their interests, their status will still be subordinated to the government. If the contract bears with civil instincts, the private capital can have fair talks with public authority based on equal status, besides, considering the essence of civil litigation is to provide a better protection of civilian interest, the result would be a reduction in unnecessary economic costs and social expenditure. From perspective of Chinese current PPP-related laws and regulations, the application of law system is not clear enough. Ministry of Finance and the Development and Reform Commission have publically affirmed that the contract dispute can be resolved by arbitration or civil litigation. However, "infrastructure and public utilities franchise management approach" issued in 2015 by six ministries and commissions still left the problem unresolved[2].

Nevertheless, if it is a civil contract, both sides of the contract cannot unilaterally change or cancel the clauses, and during common pleas, the government bears the same burden of proof as civil company does. While in the administrative contract, however quite differently, pursuant to administrative litigation, the administrative party assumes the main burden of proof, and the reason why our approach differs from the rest of the world rest in China unique national conditions[3]. Also, the administrative party enjoy privileges, which enable them to surpass the general contract, such as the right of unilateral termination and so on[4], most of which serve for the achievement of administrative purposes and the integrity of public welfare. In practice, despite of such dissimilitude between both parties, the controversy in PPP project remains difficult to apply to the administrative reconsideration framework [5].

(2) A successful business or economic model should optimize the allocation of resources, that is, people maximize their utility and all things serve their proper purpose, which is an efficient mechanism of arrangements. If the allocation of resources is unreasonable, the problem of inefficient operation emerges, along which comes the waste of human and material resources, as well as invaluable development opportunities. If this situation keeps existing in the long time, the hazard brought out therefore will certainly overweigh the occasional loss, and ultimately project failure is inevitable. To be honest, traditional state-run projects operated depending on local government funding, which in turn resulted in long-term lack of healthy competition. Theoretically, the advantage of government and social capital cooperation can combine the social efficiency of public sector with the high profitable ability of private sector, while taking advantage of the two areas will certainly obtain more than only one sector works alone. The question is whether the theory is practical, and whether the benefits of the two departments always come one step ahead shortcomings. As a matter of fact, it does not, the results of public-private partnerships often reveal as a combination of profit-making task in the private sector and inefficient jobs done in the public sector, which makes a perfect excuse for PPP projects' failure. Inconsistencies of bilateral targets also increase internal friction costs. A public agency may probably aim at maximizing social welfare, while the private partner and other stakeholders are striving to make economic profits and satisfy self-interest from a PPP project [6], which even increased the probability of failure. 
(3) China existing PPP administrative system is in severe demand of professional management knowledge and strait supervision ability, due to the absence of such, those do not satisfy the requirements of the model are implementing the PPP projects. The consequences can be embarrassing, not only quality declined in the performance of the operator's service, but the local government also start to delay payment in the prepaid subject, as well as jointly defraud with local enterprises for central and higher financial subsidies. Moreover, local governments cannot successfully complete the transition from the role of providers of public goods and services to the role of participants and quality supervisors, which makes the situation even worse. Due to the inherent dogmatism and conservative thinking, many places still maintain a power-subordinate relationship between private organizations and public authority, government departments arbitrarily use administrative power to modify the content and intervene the performance of the contract. In some areas where major public interest matters, they choose to turn a blind eye on consultation and communication with social capital, even come up with ultimate administrative decisions without notification when the contents of the contract have to be modified, leading to damages of the interests belonging to all parties.

(4) The imbalance in risk allocation and benefit sharing is the biggest obstacle in the current PPP project process. For the pursuit of tremendous profits, private capital often belittled social responsibility that they should bear under the context, and at the same time, the local governments care too much about their administrative performance, often overlooked the necessity of a reasonable dividend to guarantee the profit of private capital, which renders both sides more susceptible in the flourish PPP business. One of the most common forms of government support instruments is minimum revenue guarantee (MRG), where the government secures a minimum amount of revenue for a project[7].

\section{Newborn Requirements}

(1) From the lawyer's perspective, they should give modest and practical advice to their clients regardless of which side they belong, make it clear to them what kind of contract it is and which provision is suitable in that situation, and try to elucidate what backup they have and how does it work. All of these must be mastered by lawyers. It would save a lot of problems if both sides make an agreement on the nature of contract, though seems impossible from the perspective of administrative law. Lawyers can suggest their clients to reach an arbitration agreement or draft relative clause in the contract, which will serves as a way to avert unnecessary disputes. After all, no matter the PPP agreement is an administrative contract or a civil one, it is always lawyers' obligations to keep their clients alarmed of potential breach of contract and recommend liquidated damage compensation to them during the consultation, for these constructive advice will decrease hazard to minimum once risks occur.

(2) To avoid the above tragedy, it is necessary to realize that the essence of PPP is not just an ostensible model design, it also function as constrain of the local government budget, which means establishing value for money evaluation system, the traditional government public investment system, as well as the government procurement system reform. When it comes to lawyers' business, it should be known that the implementing agencies should select the franchisees through competitive bidding, competitive negotiation and so on when the market competition is comparatively sufficient [8]. Hence, the role of lawyers in this field is reflected in: participation in the design of tender documents, evaluation and other activities to help the government choose to reliable social capital partners; prompting social capital the possibility of low efficiency risk of the government, restricting governmental intervention on market behavior through contract design. When the subject of co-operation is established, the most significant job was to draw up the terms of the contract that both parties can accept. Careful attention must be paid to balancing public interests and private economic interests when a PPP contract is being designed.

(3) Regardless of which party is entrusted, the position of a lawyer in a PPP project is a consultant, not a supervisor, which determines the neutrality of the lawyer's role. And one thing they should always bear in mind is that lawyers are not part of the judicial system, and therefore 
they have no support and guarantee of national coercion behind their back, but lawyers can still act as a consultant in disputes. When lawyers refer to social capital issues, though the commission, they can help them realize their rights, and recognize risk prevention and take control of the development of the operating system, so that the damage caused by abuse of public power will be limited to a minimum. While receiving administrative problems, lawyers play a role in helping governments and the public sector to formulate sound decisions and policies, make recommendations and advice, draw a line of authority for the government, avoid excessive interference in private activity, and ensure its mandate correctly implemented, and despite all of this, to create a good environment for further cooperation.

(4) Based on above circumstance, it seems to be a good idea for PPP participants to follow three main principles as structured: the dominant party assumes the responsibility of risk control; the assumed risk and the return must make both ends meet; and there should exist a reasonable upper limit Therefore, a rational allocation of risk is that government departments bear the policy risk, the public demands risk, and social capital bears the construction, operation, and maintenance risks. On the basis of full knowledge of these golden rules, a capable lawyer should indicate the initial risk allocation and attached it to the invitation documents aimed for negotiation. In addition, lawyers need face-to-face communication with the bidders and illustrate what is the optimal choice during specific time. The risk allocation and sharing mechanism, to some extent, may resolve the uncertainty of the PPP project risk.

\section{Conclusion}

PPP projects in China has come to a new stage, during whose development there bound to exit a lot of new contradictions and problems, which are inevitable. It is also a great challenge for the legal community and administrative system, and lawyers must subsequently provide with inspiring advice on all kinds of problems and loopholes actively and flexibly, and that's where the value of vocation and evaluation criteria lie in. This paper aims to point out the current development of PPP project in China, make some suggestions and opinions to lawyers and other legal workers, hoping to draw more attention to this territory.

\section{Reference}

[1] The State Council, "Guiding Opinions on Investment and Financing Mechanism for Encouraging Social Investment in Key Innovation Fields," Nov, 2014.

[2] H. Cai, "The Reality and Challenge of PPP Mode in China , " http://www.ftchinese.com/story/001063831?full=y.

[3] H. L. Ji, B. H. Chi, Research on Practical Issues in the Frontier of Evidence in Administrative Litigation, China Legal Publishing House, p. 33, Jan, 2015.

[4] D. H. Ma, Case Study of Administrative Law and Administrative Procedural Law, Intellectual Property Press, p 120, Jan, 2014.

[5] L. F. Huang, Case Study of Administrative Law and Administrative Procedural Law ,China University of Political Science and Law Press, p. 154, May, 2013.

[6] Deepak K. Sharma, B. Q. Cui, J. L. Chen, Jay K. Lindly, "Balancing private and public interests in public-private partnership contracts through optimization of equity capital structure," Transportation Research Record: Journal of the Transportation Research Board, no. 2151, pp. 60-66, 2010.

[7] Nunzia Carbonara, Nicola Costantino, Roberta Pellegrino, Revenue Guarantee in Public-private Partnerships: A Fair Rrisk Allocation Model, Construction Management and Economics, vol. 32, no. 4, pp. 403-415, 2014. 